Research

Open Access

\title{
Parenteral versus enteral nutrition: effect on serum cytokines and the hepatic expression of mRNA of suppressor of cytokine signaling proteins, insulin-like growth factor-1 and the growth hormone receptor in rodent sepsis
}

\author{
Michael J O'Leary ${ }^{1}$, Aiqun Xue ${ }^{2}$, Christopher J Scarlett ${ }^{2}$, Andre Sevette ${ }^{2}$, Anthony J Kee ${ }^{2}$ and
}

Ross C Smith²

\author{
1Department of Intensive Care, The St George Hospital, Kogarah, NSW 2217, Australia \\ 2Department of Surgery, Royal North Shore Hospital, St Leonards, NSW 2065, Australia
}

Corresponding author: Michael J O'Leary, m.oleary@unsw.edu.au

Received: 2 Nov 2006 Revisions requested: 10 Feb 2007 Revisions received: 30 May 2007 Accepted: 16 Jul 2007 Published: 16 Jul 2007

Critical Care 2007, 11:R79 (doi:10.1186/cc5972)

This article is online at: http://ccforum.com/content/11/4/R79

(c) 2007 O'Leary et al.; licensee BioMed Central Ltd.

This is an open access article distributed under the terms of the Creative Commons Attribution License (http://creativecommons.org/licenses/by/2.0), which permits unrestricted use, distribution, and reproduction in any medium, provided the original work is properly cited.

\begin{abstract}
Introduction Early nutrition is recommended for patients with sepsis, but data are conflicting regarding the optimum route of delivery. Enteral nutrition (EN), compared with parenteral nutrition $(P N)$, results in poorer achievement of nutritional goals but may be associated with fewer infections. Mechanisms underlying differential effects of the feeding route on patient outcomes are not understood, but probably involve the immune system and the anabolic response to nutrients. We studied the effect of nutrition and the route of delivery of nutrition on cytokine profiles, the growth hormone-insulin-like growth factor-1 (IGF-I) axis and a potential mechanism for immune and anabolic system interaction, the suppressors of cytokine signaling (SOCS), in rodents with and without sepsis.
\end{abstract}

Methods Male Sprague-Dawley rats were randomized to laparotomy (Sham) or to cecal ligation and puncture (CLP), with postoperative saline infusion (Starve), with EN or with PN for 72 hours. Serum levels of IL- 6 and IL-10 were measured by immunoassay, and hepatic expressions of cytokine-inducible SH2-containing protein, SOCS-2, SOCS-3, IGF-I and the growth hormone receptor (GHR) were measured by real-time quantitative PCR.
Results IL-6 was detectable in all groups, but was only present in all animals receiving CLP-PN. IL-10 was detectable in all but one CLP-PN rat, one CLP-EN rat, approximately $50 \%$ of the CLP-Starve rats and no sham-operated rats. Cytokine-inducible SH2-containing protein mRNA was increased in the CLP-EN group compared with the Sham-EN group and the other CLP groups $(P<0.05)$. SOCS-2 mRNA was decreased in CLP-PN rats compared with Sham-PN rats $(P=0.07)$. SOCS-3 mRNA was increased with CLP compared with sham operation $(P<$ 0.03). IGF-I mRNA $(P<0.05)$ and GHR mRNA $(P<0.03)$ were greater in the fed CLP animals and in the Sham-PN group compared with the starved rats.

Conclusion In established sepsis, nutrition and the route of administration of nutrition influences the circulating cytokine patterns and expression of mRNA of SOCS proteins, GHR and IGF-I. The choice of the administration route of nutrition may influence cellular mechanisms that govern the response to hormones and mediators, which further influence the response to nutrients. These findings may be important in the design and analysis of clinical trials of nutritional interventions in sepsis in man.

\section{Introduction}

Early initiation of nutritional support is now considered a standard of care for patients with critical illness in intensive care units. Consensus guidelines recommend the use of enteral nutrition $(E N)$ over parenteral nutrition $(P N)$ unless there is a contraindication to using the gut [1]. Recent studies, however, have shown that it is commonly difficult to achieve adequate nutrition via the enteral route in critically ill patients [2,3]. Meta-

$\mathrm{CIS}=$ cytokine-inducible $\mathrm{SH}_{2}$-containing protein; $\mathrm{CLP}=$ cecal ligation and puncture; $\mathrm{CT}=$ cycle threshold; $E=\mathrm{PCR}$ efficiency; $\mathrm{EN}=$ enteral nutrition; $\mathrm{GH}=$ growth hormone; GHR = growth hormone receptor; IGF-I = insulin-like growth factor-1; IGFBP-I = insulin-like growth factor binding protein-1; $\mathrm{IL}=$ interleukin; $\mathrm{MNE}=$ mean normalized expression; $\mathrm{PCR}=$ polymerase chain reaction; $\mathrm{PN}=$ parenteral nutrition; $\mathrm{RT}=$ reverse transcriptase; $\mathrm{SOCS}$ $=$ suppressors of cytokine signaling; $\mathrm{TNF}=$ tumor necrosis factor. 
analyses of trials comparing EN with $\mathrm{PN}$ in critically ill patients have been published [4,5] but interpretation of the results is made difficult by the small sample sizes of individual trials and significant problems with the trial design [5]. The question therefore remains of what is the optimum nutrition regimen for critically ill patients and, in the absence of good quality clinical trial data, clinicians may need to turn to basic science investigations to aid decision-making.

The mechanism by which outcome in critically ill patients might be influenced by the early initiation of nutritional support and the route of delivery of the nutrition is not well understood. Hypotheses favoring EN include prevention of bacterial overgrowth in the stomach or bacterial translocation from the gastrointestinal tract, whereas anabolic effects of the delivered nutrients might favor PN. Any acute effects on patient outcomes, however, are most likely to be mediated through changes in the activity of the immune system. In this regard, the effect of sepsis and the influence of nutrition on tissue protein metabolism and on the functioning of the growth hormone (GH)-insulin-like growth factor-I (IGF-I) axis is of particular interest. While a derangement in the functioning of this axis, termed 'GH resistance', has been implicated as important in the pathogenesis of muscle protein catabolism in critical illness [6], it is now recognized that the activity of anabolic peptides in the $\mathrm{GH}$ family and the activity of cytokines are linked through a common cellular receptor [7]. This provides a mechanism whereby changes in the activity of this axis may influence cytokine release, and vice versa.

$\mathrm{GH}$ resistance in critical illness is characterized by a rapid and sustained decrease in circulating and tissue concentrations of IGF-I despite elevated circulating levels of $\mathrm{GH}$, the main effector of IGF-I secretion [8]. The mechanism by which $\mathrm{GH}$ resistance occurs is not fully understood, but changes both in nutrient availability and in cytokine activation are implicated. Circulating levels of IGF-I and of the insulin-like growth factor binding protein-I (IGFBP-I) are exquisitely sensitive to provision of nutrients, the former being increased and the latter being suppressed by food intake [9]. Hepatic IGFBP-I synthesis is stimulated by the cytokines IL-1, IL-6 and TNF $\alpha$ [10], and circulating IGFBP-I levels are frequently elevated in critically ill patients on intensive care unit admission [11].

Recent work has focused on the potential for a direct interaction between the GH-IGF-I axis and the immune system via the common cellular receptor. The suppressors of cytokine signaling (SOCS) proteins are inhibitors of cytokine and $\mathrm{GH}$ signaling via the janus kinase and signal transducer and activator pathway, which appear to inhibit cytokine and GH signaling as part of a classical negative feedback loop [12]. Increased hepatic mRNA of SOCS proteins has been shown to occur transiently in abdominal sepsis and to be temporally associated with the development of $\mathrm{GH}$ resistance [13]. In a study employing a rodent model of sepsis - cecal ligation and puncture $(C L P)$ - a relationship was observed between the induction of SOCS and both the presence of sepsis and the administration of PN [14]. Administration of 16 hours of PN was associated with induction of the expression of hepatic mRNA of the SOCS cytokine-inducible $\mathrm{SH}_{2}$-containing protein (CIS). This finding suggested a mechanism by which nutrition might modulate both cytokine profiles and the response to anabolic hormones such as $\mathrm{GH}$ in sepsis; however, it is not clear whether this observation represents a consequence of an effect of PN, via an effect on cytokine patterns for example, or a consequence of the provision of nutrients per se.

We have compared isocaloric and isonitrogenous PN with EN commenced immediately following CLP in rats and continued for 72 hours [15]. We found that PN alone was able to increase hepatic protein synthesis and resulted in improved net skeletal muscle protein metabolism compared with EN. Serum IGF-I was lower in CLP animals administered PN or EN when compared with the matched sham-operated groups. After CLP, PN but not EN was associated with increased IGF-I compared with the levels measured in starved animals. IGFBPI was increased in CLP animals compared with sham and increased in starved animals compared with those receiving nutrition. PN was associated with the lowest serum IGFBP-I levels in both the CLP and sham-operated groups. We hypothesized that, in sepsis, administration of nutrition and the route of its administration influence hepatic cellular responses to $\mathrm{GH}$ by modulation of SOCS proteins, either directly or via differential activation of cytokines. We therefore measured the serum concentrations of a pleiotropic cytokine (IL-6) and an anti-inflammatory (IL-10) cytokine and the expression of mRNA of SOCS proteins, of IGF-I and of the growth hormone receptor (GHR) in hepatic tissue from these animals. These results are reported in the present manuscript.

\section{Materials and methods Experimental design}

The Animal Care and Ethics Committee of Royal North Shore Hospital and the University of Technology, Sydney, Australia approved the protocol. Sixty-seven male Sprague-Dawley rats (body weight 180-220g) were received from Gore Hill Animal Research Laboratories (University of Technology, Sydney, Australia) and were housed individually in metabolic cages in a temperature-controlled $\left(23-25^{\circ} \mathrm{C}\right)$ and light-controlled (12hour light/12-hour dark) environment. The animals were initially given access to rat chow and water ad libitum for a period of 7 days. Following this acclimatization period, the animals were anesthetized by intraperitoneal injection of ketamine $(50 \mathrm{mg} /$ kg body weight) (Ketalar; Parke Davis, Sydney, NSW, Australia) and sodium pentobarbitone (30 $\mathrm{mg} / \mathrm{kg}$ body weight) (Nembutal; Rhone Merieux, Parramatta, NSW, Australia) and had a catheter aseptically implanted into the right internal jugular vein as described previously [16]. A midline laparotomy was performed and a further catheter was inserted through the anterior wall of the stomach, sutured to the stomach wall and 
exteriorized through the antero-lateral abdominal wall. This catheter was then subcutaneously tunneled to lie alongside the intravenous line.

The animals were randomized into six groups. At laparotomy, three groups underwent CLP and postoperatively received $P N$ (CLP-PN group, $n=12$ ), EN (CLP-EN group, $n=13$ ) or a continuous infusion $(0.5 \mathrm{ml} /$ hour) of isotonic saline (starvation; CLP-Starve group, $n=16$ ). The remaining three groups of animals were subjected to laparotomy only (sham operation; Sham group) and received the same feeding regimen as the CLP animals (Sham-PN group, $n=8$; Sham-EN group, $n=6$; and Sham-Starve group, $n=12$ ). The $P N$ and EN solutions were identical and provided the daily requirement of energy (1.40 MJ/kg body weight/day), amino acid nitrogen (1.3 g N/ $\mathrm{kg}$ body weight/day), essential fatty acids, vitamins, minerals and trace elements in a volume equivalent to $230 \mathrm{ml} / \mathrm{kg}$ body weight/day [16].

Following anesthesia and surgery, the animals were given 2.5 $\mathrm{ml} / 100 \mathrm{~g}$ body weight of $0.9 \%$ sodium chloride containing 0.3 $\mathrm{mg} / \mathrm{kg}$ buprenorphine intraperitoneally to provide fluid resuscitation and analgesia. The rats were then returned to their cages. Oral food (standard rat chow) was removed on the day of operation, but free access to water was continued. Further doses of intraperitoneal fluid and analgesia were administered 24 and 48 hours following operation.

\section{Cecal ligation and puncture procedure}

Following placement of the stomach catheter, in animals randomized to CLP the cecum was identified and tightly ligated at its base with great care taken to ensure that continuity of the bowel was preserved. A $23 \mathrm{G}$ needle was used to puncture the cecum in a single pass through the anterior and posterior walls. The cecum was then gently squeezed to extrude fecal matter. Only one person performed the CLP throughout the entire study to ensure consistency. In sham animals, the cecum was lifted out of the peritoneal cavity, gently squeezed and then returned.

\section{Procedures at study endpoint}

Animals were studied 72 hours following CLP or sham operations. Only animals surviving to this time point could be studied. One animal from the Sham-Starve group died prior to the study endpoint from an unknown cause; all other sham-operated animals survived. Eight CLP-PN rats, five CLP-EN rats and 15 CLP-Starve animals survived. The surviving animals were sacrificed at this time by intravenous injection of a lethal dose of sodium pentabarbitone. Full details of procedures at the time of sacrifice have been previously published [15]. Immediately following sacrifice blood was collected, via cardiac puncture, for measurement of serum levels of IL-6 and IL10. The abdomen was then opened and the liver was rapidly removed, weighed and flash frozen in liquid nitrogen. The liver was stored at $-70^{\circ} \mathrm{C}$ for subsequent analysis for the expression of mRNA of CIS, SOCS-2, SOCS-3, IGF-I and the GHR.

\section{Rat IL-6 and IL-10 immunoassays}

Serum levels of IL- 6 and IL-10 were measured using a Quantikine ${ }^{\circledR}$ Immunoassay system (R\&D Systems, Minneapolis, MN, USA) as per the manufacturer's instructions. Briefly, following the addition of $50 \mu$ lassay diluent, $50 \mu$ l serum (1:1 dilution for IL-6; undiluted for IL-10) was added to the plate and the mixture was incubated for 2 hours at room temperature. The plate was washed five times and then $100 \mu$ conjugate (anti-rat IL6-horseradish peroxidase; anti-rat IL-10-horseradish peroxidas) was then added and incubated for 2 hours at room temperature. The plate was then washed a further five times and $100 \mu$ substrate solution (equal volumes of hydrogen peroxide and the chromagen tetramethylbenzidine) was added and incubated for a further 30 minutes at room temperature. Finally, $100 \mu$ l stop solution $(\mathrm{HCl})$ was added and the absorbance was measured at $450 \mathrm{~nm}$. The minimum limit of detection of the IL-6 assay is $14 \mathrm{pg} / \mathrm{ml}$, and that for $\mathrm{IL}-10$ is $<10 \mathrm{pg} / \mathrm{ml}$.

\section{Measurement of mRNA for SOCS proteins, IGF-I and GHR}

The specific primers used for real-time quantitative RT-PCR for targeting mRNA expression values were designed with the assistance of the PRIMER 3 software [17]. The primers were: SOCS2, 5'-GCG TGA GCT CAG TCA AAC AG-3' and 5'CCC GGC TGA TGT CTT AAC AG-3'; SOCS3, 5'-CCT CAA GAC CTT CAG CTC CA-3' and 5'-CGG TTA CGG CAC TCC AGT AG-3'; CIS, 5'-GCT TGT CGA GAC CTC GAA TC3' and 5'-CAG GAT CTG GGC TGT CAC TC-3'; IGF-1, 5'TCA GTT CGT GTG TGG ACC AAG-3' and 5'-TCA CAG CTC CGG AAG CAA C-3'; GHR, 5'-ATC TTT GGC GGG TGT TCT TA-3' and 5'-TAG CTG GTG TAG CCC CAC TT-3'.

Two micrograms of total RNA treated with DNase I (Sigma, St Louis, MO, USA) was used for the RT reaction, with the cDNA stored at $-20^{\circ} \mathrm{C}$ until use. Real-time quantitative RT-PCR was performed using the iCycler iQ system (BioRad, Hercules, CA, USA) employing SYBR Green I fluorescence (Sigma) according to the manufacturer's instructions. Amplification of all mRNAs was performed in duplicate in a PCR 96-well reaction plate (BioRad). The following experimental run protocol was used. cDNA was denatured at $95^{\circ} \mathrm{C}$ for 5 minutes to activate the Hot-start Taq DNA polymerase. The amplification and quantification program was repeated 40 times $\left(95^{\circ} \mathrm{C}\right.$ for $20 \mathrm{~s}$, $60^{\circ} \mathrm{C}$ for $1 \mathrm{~min}, 72^{\circ} \mathrm{C}$ for $30 \mathrm{~s}$, with a single fluorescence measurement).

After the PCR a melting curve was constructed by increasing the temperature from $55^{\circ} \mathrm{C}$ to $95^{\circ} \mathrm{C}$ at a heating rate of $0.5^{\circ} \mathrm{C} /$ 10 seconds with continuous fluorescence measurements. The PCR efficiency $(E)$ and the cycle threshold $(C T)$ for each sample was determined using iCycle software (BioRad). The mRNA expression of SOCS2, SOCS3, CIS, IGF-1 and GHR 
Figure 1

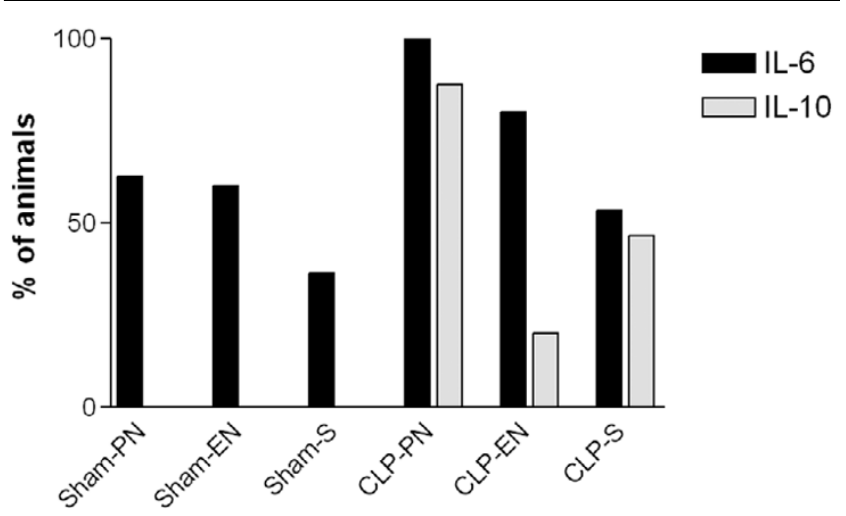

Serum levels of IL- 6 and IL-10. Percentage of animals in each of the experimental groups that had serum levels of IL- 6 and IL-10 measurable above the lower limits of detection of the assays (IL-6, $14 \mathrm{pg} / \mathrm{ml} ; \mathrm{IL}-10$, $<10 \mathrm{pg} / \mathrm{ml}$ ). Sham, sham operation; PN, parenteral nutrition; EN, enteral nutrition; S, starvation; CLP, cecal ligation and puncture.

was defined as the mean normalized gene expression (MNE) difference in target gene expression relative to the 'housekeeping gene' 18S rRNA using the following equation [18]: $\mathrm{MNE}=\left[\left(E_{\text {ref }}\right)\right.$ CTref,mean $] /\left[\left(E_{\text {target }}\right)\right.$ CTtarget,mean $]$.

\section{Statistical analysis}

Statistical evaluation of data was performed using analysis of variance with Tukey's test post hoc by Instat GraphPad version 5.02 (GraphPad Software, Inc., San Diego, CA, USA). Cytokine measurements below the lower limit of detection of the assays were allocated an arbitrary value of $1 \mathrm{ng} / \mathrm{ml}$ to permit intergroup statistical analysis. Differences detected between groups were considered significant at $P<0.05$.

\section{Results}

\section{Serum levels of IL-6 and IL-10}

Circulating IL- 6 was measurable in animals from each of the experimental groups, but only the group receiving $\mathrm{PN}$ following CLP had measurable levels in all animals. In each of the other groups a number of animals had levels below the lower limit of detection of the assay (Figure 1). Animals with undetectable levels of IL- 6 were more frequent in the Starve groups than in those receiving nutrition. The only differences for IL-6 that attained statistical significance were in animals receiving PN following CLP, where IL-6 levels were greater compared both with starvation following CLP and with PN following the sham operation (Figure 2).

Levels of IL-10 were below the lower limit of detection of the assay in all animals in the sham-operated groups and in all but one of the animals receiving EN following CLP, whereas all but one of the CLP-PN animals had measurable levels of circulating IL-10 (Figure 1). The levels of IL-10 measured in the CLP$\mathrm{PN}$ group were significantly greater than those measured in all sham-operated groups (Figure 2).
Hepatic expression of mRNA for CIS, SOCS-2, SOCS-3, IGF-I and GHR

The MNE of mRNA for CIS was significantly increased in CLPEN rats compared with Sham-EN animals and compared with animals from the other CLP groups (Figure 3). The MNE of mRNA for SOCS-2 was decreased in CLP-PN animals compared with Sham-PN animals, but was otherwise not different between the groups. The SOCS-3 mRNA MNE was significantly increased in all CLP animals when compared with sham animals from the matched feeding groups. In addition, the MNE was greater in CLP-PN animals compared with CLP-EN animals $(P=0.056)$. In the sham-operated animals, the MNE of mRNA for SOCS-3 was significantly lower in animals receiving $\mathrm{PN}$ compared with starvation animals.

The MNE of mRNA for IGF-I was in general increased by feeding compared with starvation, significant differences being observed between both the CLP-PN group and the CLP-EN group and CLP-Starve group, and between Sham-PN rats and Sham-Starve rats (Figure 4).

The MNE of mRNA for the GHR was increased by feeding compared with starvation for both CLP and sham-operated animals, but there was no difference comparing $P N$ with $E N$ in either of the surgical groups (Figure 4).

\section{Discussion}

In this study we have shown that the use of EN compared with $\mathrm{PN}$ in rats with abdominal sepsis can influence serum levels of IL- 6 and IL-10. The route of administration of nutrition also influenced the expression of mRNA of SOCS proteins in the liver. CIS was increased in sepsis by EN and SOCS-2 in sham operation by PN, whereas SOCS-3 was increased with PN after CLP and decreased with PN after sham operation. Nutrition increased the expression of mRNA of both IGF-I and the GHR, while these were not affected by sepsis. These results support a potential effect of nutrition and the route of administration of nutrition on the activity of the GH-IGF-I axis that may be mediated by cytokine production and by alterations in intracellular signaling mechanisms involving the SOCS proteins.

A number of studies in both animals and man show differences in immune system function in association with the administration of PN compared with EN [19-22]. These differences are considered to be driven principally by changes at the level of the mucosa of the gastrointestinal tract. In mice, the presence or absence of nutrients within the gut lumen has a major influence on the size and function of the gut mucosal immune system. PN is associated with a rapid fall in lymphocyte cell counts and a change in cell profiles in gut-associated lymphoid tissue; this profile change is related to decreased levels of the $\mathrm{Th}_{2}$ cytokines IL-4 and IL-10 [23]. These changes appear to be important since, compared with chow feed, PN in animals is associated with enhanced transport of endotoxin 

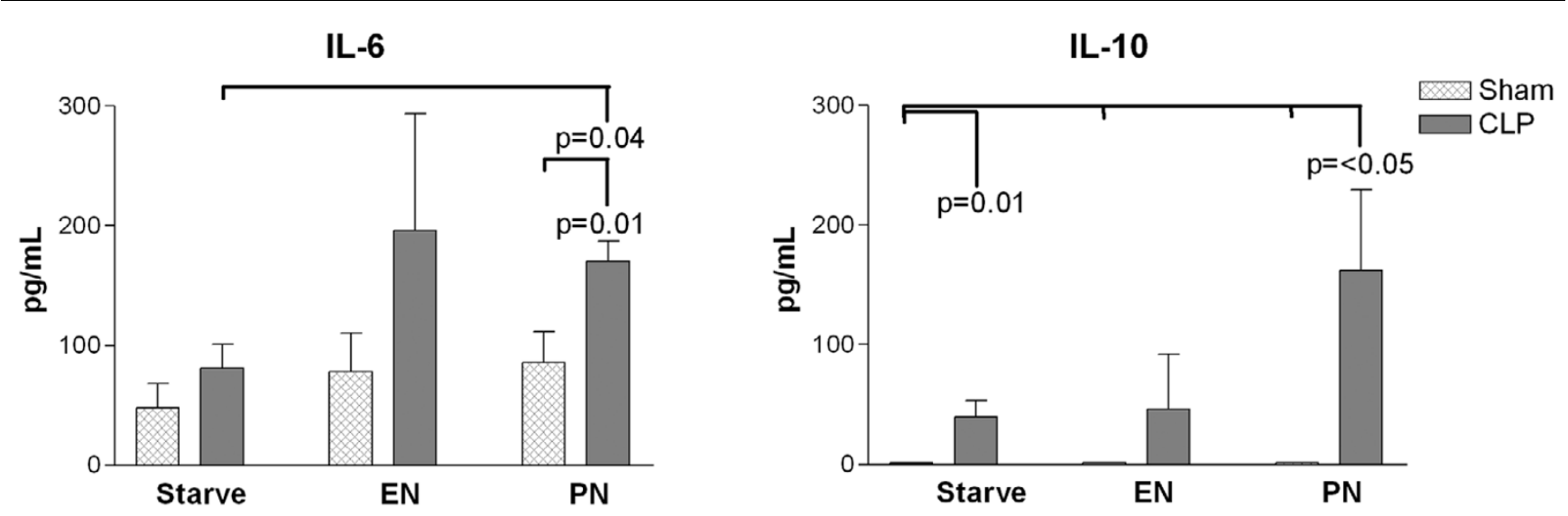

Results of serum cytokine assays. Graphs illustrate serum levels of IL-6 and IL-10, measured 72 hours after sham operation (Sham) or cecal ligation and puncture (CLP) in rats with postoperative infusion of saline (Starve), enteral nutrition (EN) or parenteral nutrition (PN). Bars and error bars represent mean values and standard error of the mean. Significant differences between groups indicated where $P<0.05$.

across the gut [24] and with increased bacterial recovery from mesenteric lymph nodes [25].

Studies in man, however, are conflicting. In human volunteers receiving $\mathrm{PN}$ versus $\mathrm{EN}$, the administration of endotoxin was associated with higher temperature, higher $\mathrm{C}$-reactive protein, higher epinephrine and higher TNF $\alpha$ responses in the PN group in one study [26] - whereas in another study the responses to endotoxin were essentially comparable, albeit with a reduced IL-6 response [27]. Notwithstanding these changes and their theoretical importance, controlled trials in man have repeatedly demonstrated an increase in infections in patients administered PN compared with EN or no nutrition $[4,5]$, a clinical observation that lends weight to differential effects of the two routes of feeding on immune function. As might be expected, 72 hours following CLP or sham operation we found a wide scatter of serum concentrations of IL- 6 and IL-10. Nonetheless, there appeared to be differences in the pattern of cytokine concentrations related both to the presence or absence of sepsis and to the nutritional management of the animals, with recovery of circulating IL- 6 and IL- 10 being more frequent in animals with sepsis administered PN. Furthermore, if these differences are explained by the effect of absence of EN on the gastrointestinal tract, it is possible that a more prolonged period of $\mathrm{PN}$, as frequently used in patients, might have produced a more marked differential in cytokine recovery between $\mathrm{PN}$ and $\mathrm{EN}$ animals.

In the clinical management of critically ill patients, balanced against concerns that use of PN predisposes to deleterious immunological changes are the risks associated with failure or delay in provision of nutrition when attempted via the enteral route. We have found that $P N$ is superior to $E N$ in increasing hepatic and muscle protein synthesis and circulating levels of IGF-I [15]. PN also resulted in significantly lower IGFBP-I levels compared with EN in septic animals, despite the greater recovery of IL-6 and IL-10 in PN-fed animals with sepsis. Our observations that $\mathrm{PN}$ was more efficacious, in comparison with EN, in influencing circulating IGF-I and IGFBP-I levels are in contrast to another rodent study comparing $P N$ and $E N$ in sepsis [28]. In that study, however, nutrition was commenced 48 hours prior to the septic insult, which is not comparable with the usual situation in patients with sepsis. Furthermore, the feeds administered were not identical.

In the present study we found increased hepatic mRNA of IGF-I in association with PN. In addition, hepatic mRNA of the GHR was increased with both PN and EN. These findings suggest that nutrition is an important stimulant to the synthesis of GHRs and thus IGF-I. We failed to demonstrate significant differences between septic and sham-operated animals in expression of mRNA of the GHR or IGF-I, nutritional differences appearing to be of more importance. The effect of sepsis on GHRs remains uncertain. After CLP both increased specific binding of $\mathrm{GH}$ to the liver [29] and reduced expression of hepatic mRNA of GHRs have been demonstrated [14]. Reduced receptor binding and mRNA was found following endotoxin challenge [30], whilst unchanged GHR mRNA was demonstrated after fecal agar pellet implantation [13]. Although the pathophysiology of $\mathrm{GH}$ resistance in sepsis is still not fully understood, the current consensus view is that low circulating concentrations of IGF-I indicate a defect in GH signal transduction that may occur either at the level of the GHR or be associated with a change in the intracellular signaling pathway for $\mathrm{GH}$.

The induction of SOCS proteins by hormones and/or cytokines has been hypothesized to inhibit $\mathrm{GH}$ signaling by a negative feedback loop involving the janus kinase and signal transducer and activator pathway [12]. Yumet and colleagues [13] have recently shown in rats with abdominal sepsis that total GHR numbers are unchanged, with the impaired IGF-I 
Figure 3

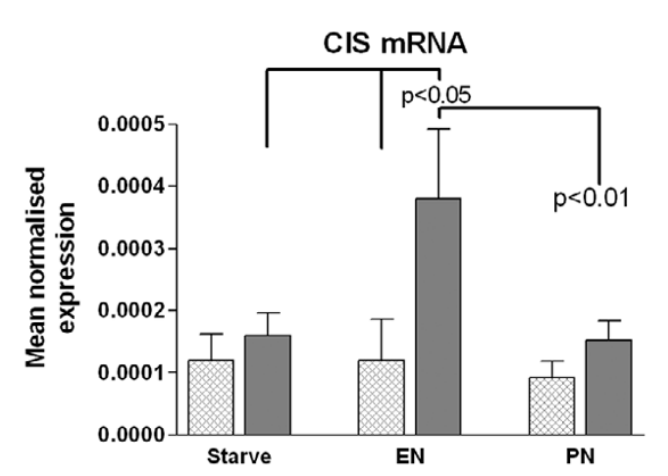

SOCS 2 mRNA

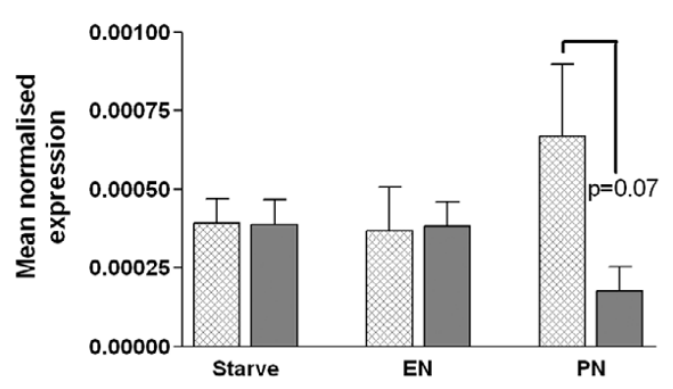

SOCS 3 mRNA

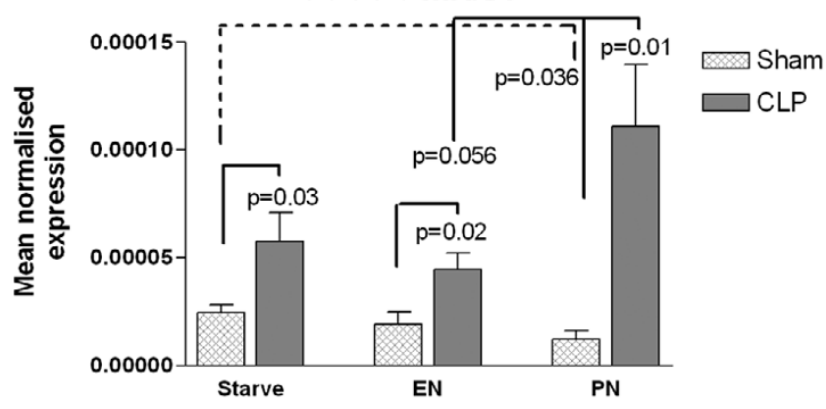

PCR measurements for cytokine-inducible $\mathrm{SH}_{2}$-containing protein, suppressors of cytokine signaling-2 and suppressors of cytokine signaling3. Bars represent the mean expression of mRNA of cytokine-inducible $\mathrm{SH}_{2}$-containing protein $(\mathrm{CIS})$, suppressors of cytokine signaling (SOCS)-2 and SOCS-3, normalized to 18S rRNA (mean normalized expression), measured in the liver from rats 72 hours after laparotomy only (Sham) or cecal ligation and puncture (CLP), with postoperative saline infusion (Starve), enteral nutrition (EN) or parenteral nutrition (PN). Error bars represent standard error of the mean. Significant differences between groups indicated where $P<0.05$.

response to $\mathrm{GH}$ being temporally related to a defect in STAT5 activation and increased SOCS mRNA expression. SOCS-1 and $\mathrm{CIS}$ expression were increased 4 hours following induction of sepsis, but by 24 hours were no different from measurements in sham-operated animals - whereas SOCS-3 expression remained elevated at 24 hours. The mechanism of the increase in SOCS expression in abdominal sepsis is
Figure 4
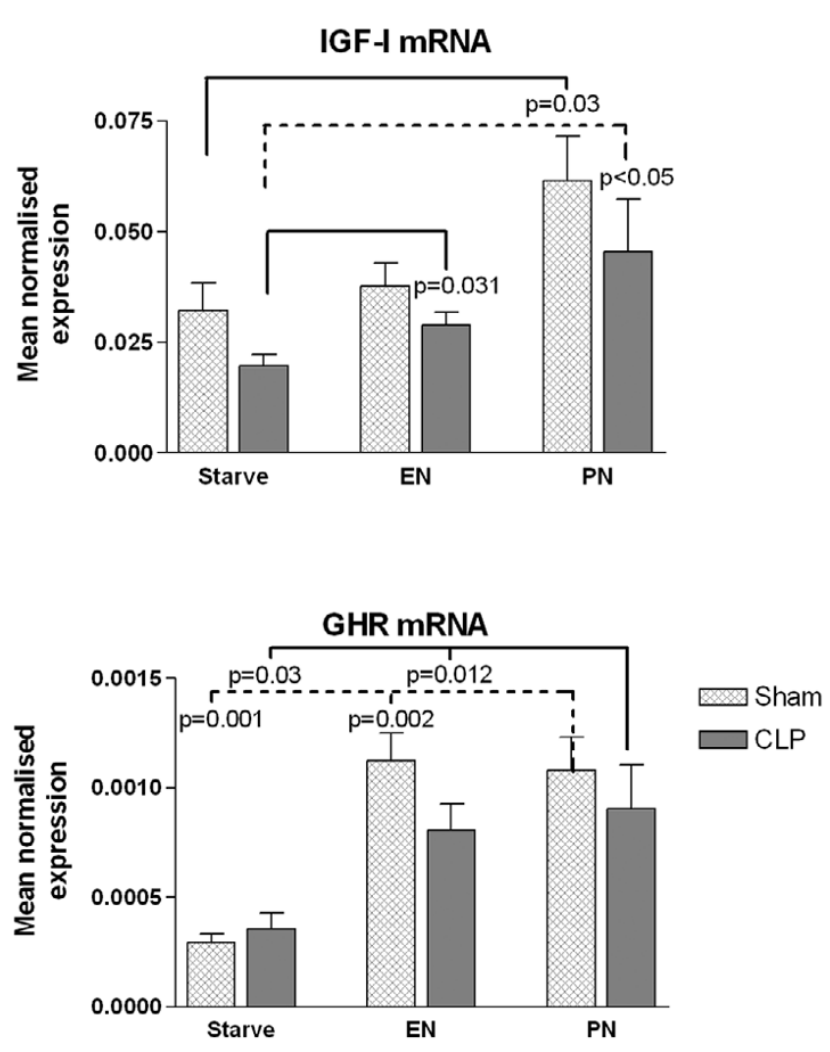

PCR measurements of insulin-like growth factor-1 and the growth hormone receptor. Bars represent the mean expression of mRNA of insulin-like growth factor-1 (IGF-I) and growth hormone receptor (GHR), normalized to 18S rRNA (mean normalized expression), measured in the liver from rats 72 hours after laparotomy only (Sham) or cecal ligation and puncture (CLP), with postoperative saline infusion (Starve), enteral nutrition (EN) or parenteral nutrition (PN). Error bars represent standard error of the mean. Significant differences between groups indicated where $P<0.05$.

unknown, and the authors of the study commented that the time course observed was consistent with that produced by endotoxin and inflammatory cytokines. Hepatic mRNA of CIS, SOCS- 2 and SOCS- 3 is transiently increased following endotoxin administration [31], while SOCS-1 expression and SOCS-3 expression were found to be increased 24 hours following CLP [14]. We now demonstrate continued induction of SOCS-3 expression at 72 hours after CLP, associated with reduced hepatic expression of mRNA of IGF-I and reduced serum IGF-I concentrations. SOCS-3 may be of particular importance in the mechanism of $\mathrm{GH}$ resistance in sepsis.

In light of the previous study that demonstrated an effect of PN on CIS expression [14], we were particularly interested in the possibility that nutrition, and possibly the route of feeding, might influence SOCS expression and thus $\mathrm{GH}$ resistance. We found greater SOCS-3 expression with PN compared with EN in sepsis, whereas in sham-operated animals the SOCS-3 expression was lowest in those given PN. In animals 
with sepsis, the CIS expression was increased by EN, and SOCS-2 expression was greater in sham-operated animals than septic animals given PN. As seen in the prior study, however, SOCS-2 expression was not affected by sepsis [14]. These differences in SOCS expression appeared independent of the induction of mRNA of the GHR or of IGF-I. Our hypothesis is that differential effects of $\mathrm{PN}$ versus $\mathrm{EN}$ on circulating levels of cytokines can explain these differences, but it seems unlikely that these effects are modulated via changes in number of GHRs. While differences in cytokine levels were observed, any mechanistic influence of these on SOCS expression cannot be determined from the present study.

We recognize that there may be problems with interpretation of the results of the present study. Although we attempted to limit the size of the ligated area of the cecum and to ensure bowel continuity was maintained, if generalized peritonitis occurred after CLP the resultant ileus and intestinal ischemia may have made nutrition by the enteral route impossible. Nonetheless, EN is recommended in clinical management guidelines for a number of conditions where intraabdominal sepsis may occur, and is said to be tolerated even in the setting of the ileus [32]. The model is therefore clinically relevant to human abdominal sepsis, in which EN use may be considered. The model has the advantage over previous studies that nutrition was commenced after the septic insult was initiated, as would most probably occur in patients, and that the EN and $\mathrm{PN}$ were identical. Furthermore, the measurements were made at a single time point 72 hours following operation. Cytokine levels change in a dynamic way after CLP, with the most pronounced changes occurring transiently well prior to 72 hours. Our experimental model precluded repeated blood sampling, but it is our contention that the differences at 72 hours are more likely to be influenced by the nutritional manipulations than would changes at earlier time points.

\section{Conclusion}

We found that nutrition and the route of nutrition in sepsis differentially influence circulating cytokine profiles and the expression of mRNA of SOCS proteins, of the GHR and of IGF-I. The present study demonstrates that the choice of nutrition route in sepsis may influence cellular mechanisms that govern the response to hormones and mediators, which further influence the response to nutrients themselves. Although our results may be heavily influenced by the design of the experiment and the experimental model, the complex interactions illustrated should be considered in the design of future trials of nutritional management in patients with sepsis.

\section{Competing interests}

MJO'L has received honoraria from Baxter Australia Pty Ltd, and from Fresenius Pharmatel Pty Ltd. The other authors declare that they have no competing interests.

\section{Key messages}

- The route of administration of nutrition (parenteral versus enteral) in sepsis influences circulating levels of IL-6 and IL-10 in rodents.

- Sepsis and the route of nutrition influence mRNA of SOCS proteins, CIS and SOCS-2, whereas SOCS-3 mRNA is increased in sepsis independent of nutrition.

- Provision of nutrition increased mRNA of the GHR and of IGF-I.

- These findings suggest that provision of nutrition and the route of delivery of nutrition in sepsis can influence circulatory and cellular mechanisms that link cytokines and the GH-IGF-I axis

\section{Authors' contributions}

MJO'L and RCS conceived of and designed the study. All authors participated in the animal handling and procedures. CJS carried out the immunoassays and $A X$ performed the PCR studies. MJO'L performed the statistical analysis. MJO'L, AX and CJS helped to draft the manuscript. All authors read and approved the final manuscript.

\section{Acknowledgements}

This study was supported by a Research Grant (2002) from the Australian \& New Zealand College of Anaesthetists, and by funding from The St George Hospital Intensive Care Research and Development Fund.

\section{References}

1. ASPEN Board of Directors and The Clinical Guidelines Task Force: Guidelines for the use of parenteral and enteral nutrition in adult and pediatric patients. J Parenter Enter Nutr 2002, 26:33S-35S.

2. O'Leary-Kelley CM, Puntillo KA, Barr J, Stotts N, Douglas MK: Nutritional adequacy in patients receiving mechanical ventilation who are fed enterally. Am J Crit Care 2005, 14:222-231.

3. Adam S, Batson S: A study of problems associated with the delivery of enteral feed in critically ill patients in five ICUs in the UK. Intensive Care Med 1997, 23:261-266.

4. Gramlich L, Kichian K, Pinilla J, Rodych NJ, Dhaliwal R, Heyland DK: Does enteral nutrition compared to parenteral nutrition result in better outcomes in critically ill adult patients? A systematic review of the literature. Nutrition 2004, 20:843-848.

5. Simpson F, Doig GS: Parenteral vs. enteral nutrition in the critically ill patient: a meta-analysis of trials using the intention to treat principle. Intensive Care Med 2005, 31:12-23.

6. Ross R, Meill J, Freeman E, Jones J, Matthews D, Preece M, Buchanan C: Critically ill patients have high basal growth hormone levels with attenuated oscillatory activity associated with low levels of insulin-like growth factor-I. Clin Endocrinol 1991, 35:47-54.

7. Waters MJ, Shang CA, Behncken SN, Tam SP, Li H, Shen B, Lobie PE: Growth hormone as a cytokine. Clin Exp Pharmacol Physiol 1999, 26:760-764.

8. Gibson FA, Hinds CJ: Growth hormone and insulin-like growth factors in critical illness. Intensive Care Med 1997, 23:369-378.

9. Hawker FH, Stewart PM, Baxter RC, Borkmann M, Tan K, Caterson ID, McWilliam DB: Relationship of somatomedin C/insulin-like growth factor I levels to conventional nutritional indices in critically ill patients. Crit Care Med 1987, 15:732-736.

10. Baxter RC: Changes in the IGF-IGFBP axis in critical illness. Best Pract Res Clin Endocrinol Metab 2001, 15:421-434.

11. Baxter RC, Hawker FH, To C, Stewart PM, Holman SR: Thirty day monitoring of insulin-like growth factors and their binding pro- 
teins in intensive care unit patients. Growth Hormone IGF Res 1998, 8:455-463.

12. Nicholson SE, Hilton DJ: The SOCS proteins: a new family of negative regulators of signal transduction. J Leukoc Biol 1998, 63:665-668.

13. Yumet G, Shumate ML, Bryant P, Lang $\mathrm{CH}$, Cooney RN: Hepatic growth hormone resistance during sepsis is associated with increased suppressors of cytokine signaling expression and impaired growth hormone signaling. Crit Care Med 2006, 34:1420-1427.

14. Johnson TS, O'Leary M, Justice SK, Maamra M, Zarkesh-Esfahani SH, Furlanetto R, Preedy VR, Hinds CJ, El Nahas AM: Differential expression of suppressors of cytokine signalling genes in response to nutrition and growth hormone in the septic rat. $J$ Endocrinol 2001, 169:409-415.

15. Scarlett CJ, O'Leary MJ, Kee AJ, Nielsen A, Sevette A, Baxter RC, Smith RC: Survival and protein turnover in severe abdominal sepsis: parenteral versus enteral nutrition. Clin Nutr 2004, 23:1135-1145

16. Kee AJ, Smith RC: The effect of the rate and route of nutrient delivery on total body organ composition in rats. Nutrition 1996, 12:180-188.

17. Rozen S, Skaletsky H: Primer3 on the WwW for general users and for biologist programmers. Methods Mol Biol 2000, 132:365-386

18. Baker MK, Mikhitarian K, Osta W, Callahan K, Hoda R, Brescia F, Kneuper-Hall R, Mitas M, Cole DJ, Gillanders WE: Molecular detection of breast cancer cells in the peripheral blood of advanced-stage breast cancer patients using multimarker real-time reverse transcription-polymerase chain reaction and a novel porous barrier density gradient centrifugation technology. Clin Cancer Res 2003, 9:4865-4871.

19. Kudsk KA: Effect of route and type of nutrition on intestinederived inflammatory response. Am J Surg 2003, 185:16-21.

20. Ueno C, Fukatsu K, Kang W, Maeshima Y, Moriya T, Hara E, Nagayoshi H, Omata J, Saito H, Hiraide H, Mochizuki H: Route and type of nutrition influence nuclear factor $\kappa B$ activation in peritoneal resident cells. Shock 2005, 24:382-387.

21. Cui X-L, Iwasa M, Kuge H, Sasaguri S, Ogoshi S: Route of feeding influences the production and expression of tumor necrosis factor $\alpha$ in burned rats. Surg Today 2001, 31:615-625.

22. Moore FA, Feliciano DV, Andrassy RJ, McArdle AH, Booth FV, Morgenstein-Wagner TB, Kellum JM Jr, Welling RE, Moore EE: Early enteral feeding, compared with parenteral, reduces postoperative septic complications. The results of a meta-analysis. Ann Surg 1992, 216:172-183.

23. Wu Y, Kudsk KA, DeWitt RC, Tolley EA, Li J: Route and type of nutrition influence IgA-mediated intestinal cytokines. Ann Surg 1999, 229:662-668.

24. Gonnella PA, Helton WS, Robinson M, Wilmore D: O-side chain of Escherichia coli endotoxin 0111:B4 is transported across the intestinal epithelium in the rat: evidence for increased transport during total parenteral nutrition. Eur J Cell Biol 1992, 59:224-227.

25. Alverdy JC, Aoys E, Moss GS: Total parenteral nutrition promotes bacterial translocation from the gut. Surgery 1988 , 104:185-190.

26. Fong $\mathrm{Y}$, Marano MA, Barber A, He W, Moldawer LL, Bushman ED, Coyle SM, Shires GT, Lowry SF: Total parenteral nutrition and bowel rest modify the metabolic response to endotoxin in humans. Ann Surg 1989, 210:449-457.

27. Santos AA, Rodrick ML, Jacobs DO, Dinarello CA Wolff SM, Mannick JA, Wilmore DW: Does the route of feeding modify the inflammatory response? Ann Surg 1994, 220:155-163.

28. Wojnar MM, Fan J, Li YH, Lang $\mathrm{CH}$ : Endotoxin-induced changes in IGF-I differ in rats provided enteral vs parenteral nutrition. Am J Physiol 1999, 276:E455-E464.

29. O'Leary MJ, Quinton N, Ferguson CN, Preedy VR, Ross RJ, Hinds $\mathrm{CJ}$ : In rats with sepsis, the acute fall in IGF-I is associated with an increase in circulating growth hormone-binding protein levels. Intensive Care Med 2000, 26:1547-1552.

30. Defalque D, Brandt N, Ketelsegers JM, Thissen JP: GH insensitivity induced by endotoxin injection is associated with decreased liver GH receptors. Am J Physiol 1999, 276:E565-E572.

31. Mao Y, Ling PR, Fitzgibbons TP, McCowen KC, Frick GP, Bistrian $\mathrm{BR}, \mathrm{Smith} \mathrm{RJ}$ : Endotoxin-induced inhibition of growth hormone receptor signaling in rat liver in vivo. Endocrinology 1999, 140:5505-5515.

32. Meier R, Beglinger C, Layer P, Gullo L, Keim V, Laugier R, Friess $\mathrm{H}$, Schweitzer M, Macfie J, the ESPEN Consensus Group: ESPEN guidelines on nutrition in acute pancreatitis: European Society of Parenteral and Enteral Nutrition. Clin Nutr 2002, 21:173-183. 